\title{
Preoperative predictors of health-related quality of life changes (EQ-5D and EQ VAS) after total hip and knee replacement: a systematic review
}

\author{
Caroline Schatz ${ }^{1 *}$, Nina Klein ${ }^{2}$, Antonia Marx ${ }^{2}$ and Peter Buschner ${ }^{3}$
}

\begin{abstract}
Background: Patient-reported outcomes are of ever-increasing importance in medical decision-making. The EQ-5D is one of the generic instruments measuring health-related quality of life (HRQOL) in arthroplasty. This review aimed to identify possible predictors of HRQoL changes for patients undergoing total knee replacements (TKR) or total hip replacements (THR).
\end{abstract}

Methods: A systematic literature review according to the PRISMA guidelines was conducted, searching several databases. Preoperative to postoperative HRQoL changes were evaluated in patients undergoing THR or TKR, using the EQ-5D visual analog scale (VAS) or the preference-based EQ-5D Index were evaluated. Articles were considered with prospectively or retrospectively collected data, as well as registry data, each with statistical analyses of patient-related factors.

Results: Eight hundred eighty-two articles were found, of which 21 studies met the inclusion criteria. Predictors were distinguished in alterable and non-alterable ones. The EQ-5D Index indicated a tendency towards beneficial improvements for patients with a high body mass index (BMI) (>40) and no significant results for the VAS. Additionally, one study found that patient education and preoperative physiotherapy appeared to enhance HRQoL. Some evidence indicated that male gender was negatively associated with changes in the VAS and the EQ-5D Index, but one study reported the opposite. Changes in VAS and EQ-5D Index were lower for older patients, whereas a higher educational level seemed to be advantageous. A high Charnley class led to deteriorating changes in VAS, although a high Kellgren Lawrence classification was positively associated with the EQ-5D Index, in a limited number of studies. For all results, clinical relevance was calculated differently and mainly reported as uncertain or small.

Conclusions: The literature on this topic was weak and offers only limited guidance. Results for alterable predictors, such as the BMI, indicated valuable improvements for highly obese patients. Further, high-quality research is required to support medical decision-making.

Level of evidence: Level IV, according to the OCEBM Levels of Evidence Working Group.

Keywords: PROM, Health-related quality of life, EQ-5D, Hip, Knee

\footnotetext{
*Correspondence: schatz@bwl.Imu.de

${ }^{1}$ Ludwig-Maximilians-Universität München, LMU Munich School

of Management, Institute of Health Economics and Health Care Management, Munich, Germany

Full list of author information is available at the end of the article
}

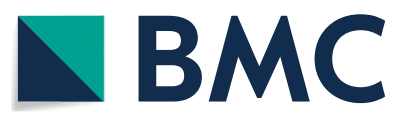

(c) The Author(s) 2022. Open Access This article is licensed under a Creative Commons Attribution 4.0 International License, which permits use, sharing, adaptation, distribution and reproduction in any medium or format, as long as you give appropriate credit to the original author(s) and the source, provide a link to the Creative Commons licence, and indicate if changes were made. The images or other third party material in this article are included in the article's Creative Commons licence, unless indicated otherwise in a credit line to the material. If material is not included in the article's Creative Commons licence and your intended use is not permitted by statutory regulation or exceeds the permitted use, you will need to obtain permission directly from the copyright holder. To view a copy of this licence, visit http://creativecommons.org/licenses/by/4.0/. The Creative Commons Public Domain Dedication waiver (http://creativeco mmons.org/publicdomain/zero/1.0/) applies to the data made available in this article, unless otherwise stated in a credit line to the data. 


\section{Background}

Total joint replacements are a recommended surgical procedure for patients with advanced osteoarthritis (OA). These interventions are performed to reduce pain and improve the function of joints for patients [1]. Despite the surgical success, there are patients who remain dissatisfied with total knee replacement (TKR) or total hip replacement (THR) [2, 3].

Patient-reported outcome measures are tools for the measurement of health-related quality of life (HRQoL). HRQoL mirrors the view of the individual patient and captures different aspects of this persons' life, additionally to the perspective of the physician. According to Brooks (1996) [4] one of these measurements is the EQ-5D questionnaire, which quantifies the current state of health with a generic instrument. The questionnaire exists in two versions, the EQ-5D-3L and EQ-5D-5L, where the EQ-5D-5L is considered as the successor to the EQ-5D-3L [5, 6]. Both contain five dimensions (mobility, selfcare, usual activities, pain/discomfort, anxiety/ depression) with each having three problem levels in the former and five in the latter. The vertical visual analog scale (VAS) completes the questionnaire. Patients evaluate their own, current health state by setting a mark between 0 being the worst health state and 100 being the best health state [4]. The psychometric properties of the EQ-5D were investigated for TKR and THR finding, among others, that the 5-L version showed improved performance [7]. Yet for THR, the EQ VAS scores were found to be highly correlated, and their estimates for different problem levels to be largely consistent between the $3 \mathrm{~L}$ and $5 \mathrm{~L}$-versions [8-10].

A number of previous studies have examined predictors of postoperative HRQoL in patients undergoing TKR or THR. Studies have shown that mental health, especially pre-operative anxiety, depression, pain and poor function, predict a poorer post-operative HRQoL [11]. Socioeconomic status [12] or socioeconomic variables, such as age, gender and education were commonly used predictors for postoperative outcomes [13, 14], as well as obesity [15]. Additionally, preoperative function and preoperative radiological osteoarthritis seemed to be important predictors of postoperative HRQoL [16]. Newer approaches even used machine-leaning approaches to predict outcomes more precisely [17], or investigated predictors for disease-specific HRQoL instruments [12]. A detailed investigation about the predictive power of value sets, based on the EQ-5D-3L, showed that the preoperative surgery risk score, classified according to the American Society of Anesthesiologists (ASA), predicted HRQoL outcomes 1 year postoperatively [18].

This systematic review aimed to examine preoperative predictors for the improvement of preoperative to postoperative EQ-5D. The EQ-5D Index with the VAS is often applied in routine data collection pre/post THR and TKR procedures, for example in Sweden or the UK [18]. Since the EQ-5D with the VAS is a generic instrument, an analysis of predictors for improvement might identify alternative predictors to disease specific measurements such as the Western Ontario and McMaster Universities Osteoarthritis Index (WOMAC) [12]. The EQ-5D questionnaire also comprises questions about general health, especially psychological problems, that are often not considered in disease-specific measurements. Predicting the outcome of THR or TKR, in terms of HRQoL, remains a challenging but necessary task for researchers and practitioners. For this literature review, studies were selected that evaluated the improvement in HRQoL preoperatively to postoperatively, with predictors measured preoperatively. As some predictors, like age, were unchangeable and others like the BMI, might be changed, this review classified predictors as alterable and non-alterable. Additionally, a structural summary of the significance of predictors and investigation of the minimum clinical important difference (MCID) was provided, to contribute to the current discussion about HRQoL.

\section{Material and Methods}

The method of this systematic literature review followed the PRISMA guidelines [19], with a narrative synthesis, without a meta-analysis. Variables in published studies, which improved HRQoL for patients with OA undergoing THR and TKR, were investigated. Beside the detection of predictors, the MCID was investigated, as well as the statistical significance. According to Page (2014) [20], especially in studies with patient-centered outcome measurements the clinical meaningfulness had to be considered, because the clinical insight was not adequately reflected by statistical significance. The $p$-value in statistics was chosen by the researcher and determines only a decision whether to decline the hypothesis or not, but this did not imply whether the change in HRQoL was meaningful for the patient [20]. The MCID was calculated for HRQoL instruments differently and an adaptation to the specific questionnaire was suggested [21]. A review revealed 11 methods to calculate the MCID for orthopedics [22]. Table 1 showed an excerpt of calculation methods for the MCID that were applied in the studies included in this review.

\section{Quality assessment}

The quality of evidence was assessed according to the GRADE guidelines [27]. All included studies were examined by one author [CS] and at least a second author [NK, AM]. Disagreements were discussed among CS, NK, and AM leading to the finding of a collaborative solution. 
Table 1 Minimum clinical important differences (MCID)

\begin{tabular}{lllll}
\hline Author & HRQoL & Indication & Outcome & Method \\
\hline Walters et al. (2005) [23] & EQ-5D-3L, UK utility index & THR & Mean: 0,074 (-0.011 to 0.140) & Anchor-based (patient questions) \\
Impellizzeri et al. (2012) [24] & EQ-5D-3L, EQ VAS Score & $\begin{array}{l}\text { Femoroacetabu- } \\
\text { lar impingement }\end{array}$ & I5 points VAS & Anchor-based (patient questions) \\
Norman et al. (2003) [25] & HRQoL in general & & Half of standard deviation & Distribution-based (review of 33 studies) \\
Cohen (1988) [26] & Effect size in general & & 0.20 (for a little effect) & Distribution-based (distance of means) \\
\hline
\end{tabular}

The GRADE [27] assessment rated observational studies generally with low or very low quality. All studies in this review are observational and therefore, a low rating was the best assessment a study could achieve. According to Guyatt et al. (2011) [28], there are four further study limitations (inappropriate eligibility criteria, flawed outcome measurement, improper control of covariates, incomplete follow-up) that might increase the risk of bias in observational studies, and were considered in this review [29-32].. Details were provided in the supplementary material, as Additional file 1. All included studies developed transparent eligibility criteria and measured predictors and outcomes with an EQ-5D instrument. Covariates were controlled in several ways; mainly by alternating different variables in the statistical models. The statistical analyses were highly heterogenous with some studies including preoperative HRQoL in their model, whereas others used univariate analyses. Hence, collinearity could be an issue in some studies. The covariates for each study were provided in the supplementary material, as Additional file 2.

\section{Search strategy}

The Cochrane Library and PubMed search engines were searched for articles until September 15, 2020 and updated on October 1, 2021. A detailed subdivision in the underlying databases was provided in Fig. 1. The PICO framework from the Cochrane Handbook [33] was applied, with the following search terms (Table 2).

\section{Study selection}

Inclusion criteria concerning the study design were randomized controlled trials (RCTs), trials, prospective studies and retrospective observational or register-based studies. These assessed predictive factors for HRQoL changes within OA patients who underwent primary TKR and THR. The HRQoL change was measured using the EQ-5D before and at least 3 months after the surgery with the original EQ-5D Index and VAS from the EuroQoL group [4]. To be included studies were required to assess the effect of no less than one preoperative predictive variable, but studies examining only individual comorbidities or multimorbidity were excluded. Studies were included if they were written in English or German languages.

\section{Data extraction}

The software EndNote ${ }^{\circledR}$ was used to find duplicates and to screen titles and abstracts. Selected articles for fulltext screening were examined using following, predefined examination criteria. Apart from the author, title and year of publication, the country, indication, joint, study design, method, time period, number of participants, response rate, applied level of questionnaire, and MCID were collected using Microsoft Excel $^{\circledR}$ spreadsheets. A template was created and filled manually by CS, NK, and AM, from the studies. All studies were downloaded as pdfs and relevant text passages were marked digitally, with Acrobat Reader $D^{\circledR}$. The explanatory variables were gathered and then distinguished as alterable or nonalterable ones. Further analysis was conducted regarding the effects of individual predictors on the EQ-5D Index and VAS scale with Microsoft Excel ${ }^{\circledR}$.

\section{Results}

Overall, 882 articles were found in both search engines. After duplicates were removed and titles and abstracts screened 35 articles were eligible. Of these, 14 articles were excluded, because the EQ-5D change was not the primary outcome variable. As a result, 21 articles were included in the qualitative analysis.

\section{Descriptive results}

All 21 studies were conducted in the US or Europe. Mostly registry data were applied, either nation-wide or institution wide. Nation-wide, the Swedish Hip Arthroplasty Register was applied six times, the UK registry twice and the Dutch registry once. The number of patients varied widely from 147 up to 53.498, and the time period until the post-operative survey ranged from 3 months to 7 years, although several studies reported more than one postoperative response 

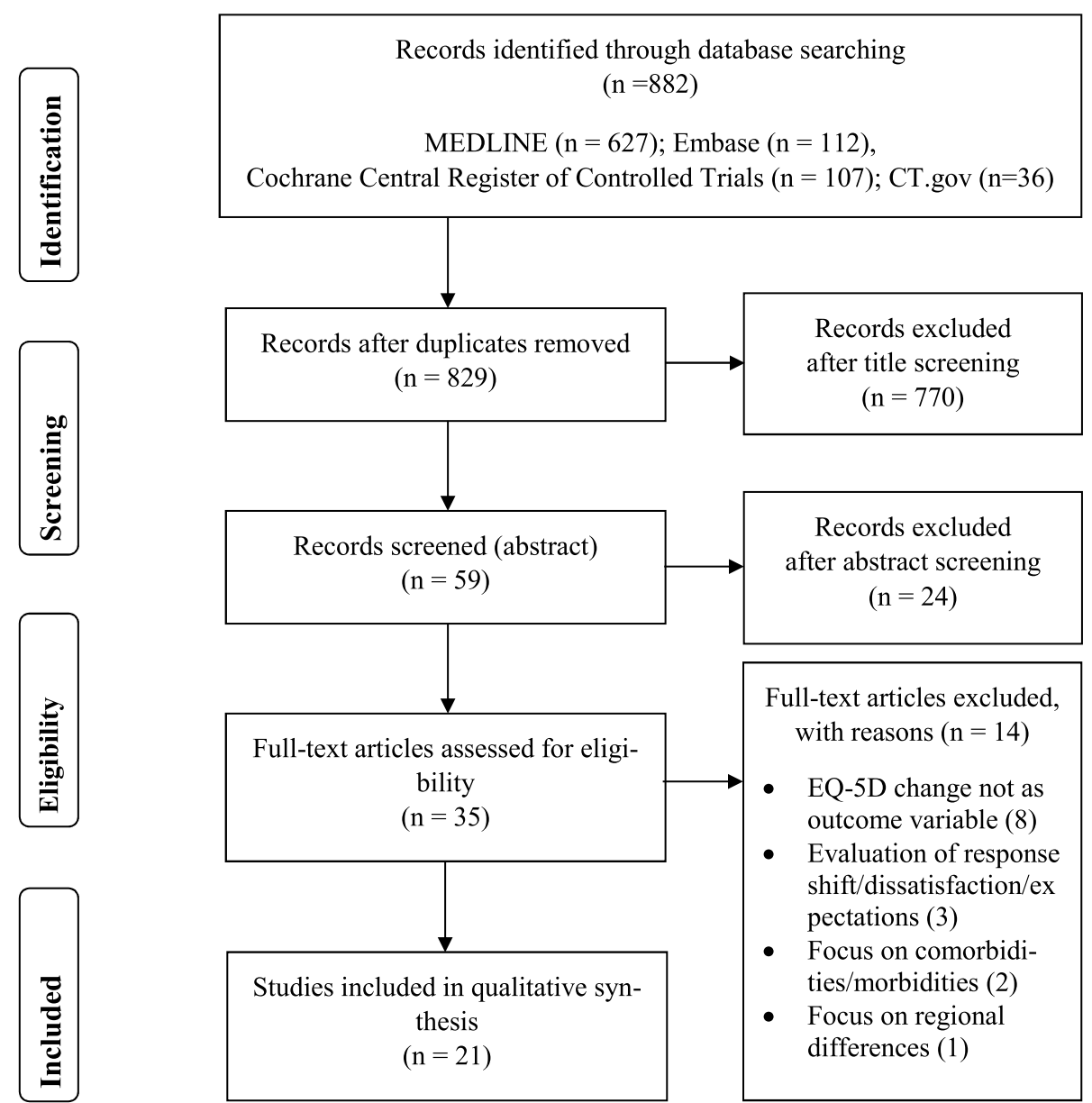

Full-text articles excluded, with reasons $(n=14)$

- EQ-5D change not as outcome variable (8)

- Evaluation of response shift/dissatisfaction/ex pectations (3)

- Focus on comorbidities/morbidities (2)

- Focus on regional differences (1)

Fig. 1 PRISMA flow diagram

Table 2 Search strategy with PICO

\begin{tabular}{ll}
\hline PICO & Search terms \\
\hline Participants & hip OR knee \\
Interventions & artificial OR arthroplasty OR endoprosthesis OR prosthesis OR replacement \\
Comparisons & driver OR impact OR influence* OR factor OR predict* OR effect* OR \\
& $\begin{array}{l}\text { importance OR change* OR shift OR improve* OR increase* OR trajector* } \\
\text { OR difference OR gain* }\end{array}$ \\
Outcomes & EuroQol OR EQ-5D* OR EQ. 5D* \\
\hline
\end{tabular}

with different time periods. A wide variety of multiple regressions and tests were applied, as methods for the analysis (Table 3 ).

The results were subdivided into alterable predictors and non-alterable predictors. Alterable predictors encompassed the BMI, preoperative patient education, knowledge, and physiotherapy. Non-alterable predictors were defined as age, gender, level of education, Charnley class, Kellgren Lawrence (KL) classification, Ahlbäck classification, ASA-score/no previous operation and anxiety/depression Table 4.

\section{Alterable predictors \\ BMI}

The influence of the BMI on HRQoL changes was investigated for TKR by Baker et al. (2012) [34], finding EQ-5D Index changes to increase with a higher preoperative BMI, subdivided into three groups (BMI of 15-24; 
Table 3 Descriptive results

\begin{tabular}{|c|c|c|c|c|c|c|}
\hline Author & Country & Joint (total) & Study design/data & Method & Time to follow-up & Number of patients \\
\hline $\begin{array}{l}\text { Baker et al. (2012) } \\
\text { [34] }\end{array}$ & UK & Knee & $\begin{array}{l}\text { National Joint Regis- } \\
\text { try Data }\end{array}$ & $\begin{array}{l}\text { Adjusted and } \\
\text { unadjusted multiple } \\
\text { regressions }\end{array}$ & 6 to 12 months & 13.673 \\
\hline $\begin{array}{l}\text { Foster et al. (2015) } \\
\text { [35] }\end{array}$ & USA & Hip & $\begin{array}{l}\text { Institution-wide } \\
\text { registry }\end{array}$ & F-tests & Not given & 435 \\
\hline $\begin{array}{l}\text { Galea et al. (2019) } \\
\text { [36] }\end{array}$ & USA & Hip & $\begin{array}{l}\text { Prospective, interna- } \\
\text { tional, multi-center } \\
\text { study }\end{array}$ & $\begin{array}{l}\text { piece-wise linear } \\
\text { mixed effects models }\end{array}$ & $\begin{array}{l}3 \text { months, } \\
1,3,5,7 \text { years }\end{array}$ & 976 \\
\hline $\begin{array}{l}\text { Giesinger et al. (2021) } \\
\text { [37] }\end{array}$ & Switzerland & Knee & $\begin{array}{l}\text { Institution-wide } \\
\text { study }\end{array}$ & Linear mixed models & 12 months & 1.565 \\
\hline $\begin{array}{l}\text { Gordon et al. (2014) } \\
\text { [38] }\end{array}$ & Sweden & Hip & $\begin{array}{l}\text { Swedish Hip Arthro- } \\
\text { plasty Register }\end{array}$ & $\begin{array}{l}\text { Robust covariance } \\
\text { matrix }\end{array}$ & 12 months & 27.245 \\
\hline $\begin{array}{l}\text { Greene et al. (2014) } \\
\text { [39] }\end{array}$ & Sweden & Hip & $\begin{array}{l}\text { Swedish Hip Arthro- } \\
\text { plasty Register }\end{array}$ & $\begin{array}{l}\text { Linear regression } \\
\text { models }\end{array}$ & 12 months & 11.464 \\
\hline $\begin{array}{l}\text { Jenkins et al. (2013) } \\
\text { [40] }\end{array}$ & UK & Hip/Knee & Regional registry & $\begin{array}{l}\text { Two-way repeated } \\
\text { measures analysis of } \\
\text { variance }\end{array}$ & 12 months & 671 \\
\hline Joly et al. (2020) [41] & Canada & Hip/Knee & Retrospective study & $\begin{array}{l}\text { descriptive analysis, } \\
\text { one-way analysis } \\
\text { of variance test, } \\
\text { Chi-squared test, } \\
\text { multivariate linear } \\
\text { regression }\end{array}$ & 3 and 12 months & 53.498 \\
\hline $\begin{array}{l}\text { Koekenbier et al. } \\
\text { (2016) [42] }\end{array}$ & $\begin{array}{l}\text { Finland, Greece, Ice- } \\
\text { land, Spain, Sweden }\end{array}$ & Hip/Knee & $\begin{array}{l}\text { Prospective cohort } \\
\text { study }\end{array}$ & General linear model & 6 months & 762 \\
\hline $\begin{array}{l}\text { Manalo et al. (2018) } \\
\text { [43] }\end{array}$ & USA & Knee & $\begin{array}{l}\text { Institution-wide } \\
\text { registry }\end{array}$ & Paired t-tests & 12-17 months & 167 \\
\hline $\begin{array}{l}\text { McLawhorn et al. } \\
\text { (2017) [44] }\end{array}$ & USA & Hip & $\begin{array}{l}\text { Institution-wide } \\
\text { registry }\end{array}$ & $\begin{array}{l}\text { Pearson's chi-square } \\
\text { test, regression } \\
\text { analysis }\end{array}$ & 2 years & 2.733 \\
\hline $\begin{array}{l}\text { Mohaddes et al. } \\
\text { (2019) [45] }\end{array}$ & Sweden & Hip & $\begin{array}{l}\text { Swedish Hip Arthro- } \\
\text { plasty Register }\end{array}$ & Non-parametric tests & 12 months & 1.008 \\
\hline $\begin{array}{l}\text { Ostendorf et al. } \\
\text { (2004) [46] }\end{array}$ & USA & Knee & $\begin{array}{l}\text { Institution-wide } \\
\text { registry }\end{array}$ & $\begin{array}{l}\text { Pair-wise compari- } \\
\text { sons using the Holm } \\
\text { step-down Bonfer- } \\
\text { roni method }\end{array}$ & 2 years & 147 \\
\hline $\begin{array}{l}\text { Peters et al. (2020) } \\
\text { [47] }\end{array}$ & Netherlands & Hip & $\begin{array}{l}\text { Retrospective obser- } \\
\text { vational study, Dutch } \\
\text { Arthroplasty Register }\end{array}$ & $\begin{array}{l}\text { Multivariable linear } \\
\text { regression analysis }\end{array}$ & 3 and 12 months & 22.357 \\
\hline $\begin{array}{l}\text { Rehman et al. (2020) } \\
\text { [48] }\end{array}$ & Norway & Knee & Longitudinal study & $\begin{array}{l}\text { Paired sample t-tests, } \\
\text { kappa statistics, Pear- } \\
\text { son correlation coef- } \\
\text { ficients, multivariable } \\
\text { regression analysis }\end{array}$ & 12 months & 245 \\
\hline $\begin{array}{l}\text { Rolfson et al. (2011) } \\
\text { [49] }\end{array}$ & Sweden & Hip & $\begin{array}{l}\text { Swedish Hip Arthro- } \\
\text { plasty Register }\end{array}$ & $\begin{array}{l}\text { Mann-Whitney } \\
\text { U-test, multivariable } \\
\text { regression }\end{array}$ & 12 months & 34.960 \\
\hline Scott et al. (2021) [50] & Scotland & Knee & $\begin{array}{l}\text { Institution-wide } \\
\text { study }\end{array}$ & $\begin{array}{l}\text { Parametric and } \\
\text { non-parametric tests, } \\
\text { multivariable linear } \\
\text { regressions }\end{array}$ & 12 months & 259 \\
\hline $\begin{array}{l}\text { Steinhaus et al. } \\
\text { (2020) [51] }\end{array}$ & UK & Knee & $\begin{array}{l}\text { Institution-wide } \\
\text { registry }\end{array}$ & $\begin{array}{l}\text { Pair-wise compari- } \\
\text { sons using the Holm } \\
\text { step-down Bonfer- } \\
\text { roni method. }\end{array}$ & 2 years & 2.472 \\
\hline $\begin{array}{l}\text { Tilbury et al. (2016) } \\
\text { [52] }\end{array}$ & Netherlands & Hip Knee & $\begin{array}{l}\text { Prospective cohort } \\
\text { study }\end{array}$ & $\begin{array}{l}\text { Mann-Whitney-U-test } \\
\text { and multivariable } \\
\text { linear regressions }\end{array}$ & & 573 \\
\hline $\begin{array}{l}\text { Torisho et al. (2019) } \\
\text { [53] }\end{array}$ & Sweden & Hip & $\begin{array}{l}\text { Swedish Hip Arthro- } \\
\text { plasty Register }\end{array}$ & $\begin{array}{l}\text { Multiple linear } \\
\text { regression }\end{array}$ & 12 months & 30.756 \\
\hline
\end{tabular}


Table 3 (continued)

\begin{tabular}{|c|c|c|c|c|c|c|}
\hline Author & Country & Joint (total) & Study design/data & Method & Time to follow-up & Number of patients \\
\hline $\begin{array}{l}\text { Williams et al. (2013) } \\
\text { [54] }\end{array}$ & UK & $\begin{array}{l}\text { Knee (total/unicom- } \\
\text { partmental) }\end{array}$ & $\begin{array}{l}\text { Prospective cohort } \\
\text { study }\end{array}$ & $\begin{array}{l}\text { Linear regression } \\
\text { models }\end{array}$ & 6 months & 2.126 \\
\hline
\end{tabular}

25-39; 40-60). After adjusting for age, gender, ASA grade, comorbidities and health ratings, no significant impact of any BMI group was found on the EQ-5D Index change. Also, the results were not considered to be clinically relevant, and the VAS scores were not significant, irrespective of the adjustments and the BMI group [34]. Partly in contrast, Steinhaus et al. (2020) [51] investigated no significant differences in VAS changes between different BMI groups, measured according to the WHO definition [55], but for the EQ-5D Index. Equally, for the EQ-5D Index, Giesinger et al. (2021) [37] found no significant results on the BMI classes for TKR, considering age, gender and the interaction of time point (preoperative and 12-month follow-up) by BMI group, as covariates. Patients from all BMI groups experienced HRQoL improvements and patients with a BMI in obesity classes II and III experienced the largest EQ-5D Index improvements [37, 44, 51].

THR was evaluated by McLawhorn et al. (2017) [44]: for the VAS no significant impact of the BMI, according to the WHO classification [55], was revealed. However, for the EQ-5D Index, obese patients significantly improved their HRQoL by THR, especially patients with a $\mathrm{BMI}>40$ and underweight patients with a $\mathrm{BMI}<18,5$ [44]. In contrast, Foster et al. (2015) [35] also evaluated the impact of BMI, with three subgroups $(<30 ; 30-40$; $>40$ ), on HRQoL changes and found no significant influence for the VAS or the EQ-5D Index changes [35]. Peters et al. (2020) [47] examined the influence of the EQ-5D Index on the BMI, distinguished between lower than 30 and above 30. It was confirmed that patients with a high BMI benefit more from THR, but with a small Cohen's $d$, indicating small clinical relevance [47]. It is important to mention that Peters et al. (2020) [47] and Foster et al. (2015) [35] did not evaluate underweight patients in a separate BMI class. Using long-term results after 1 year, Galea et al. (2019) [36] showed that obese patients $(\mathrm{BMI} \geq 30)$ steadily declined in the EQ-5D Index after an increase in HRQoL in the first 3 months after THR.

\section{Preoperative patient education, knowledge, and physiotherapy}

A cross-cultural study by Koekenbier et al. (2016) [42] evaluated the influence of expected and received patient education on HRQoL changes. The hypothesis, that patients, who received their expected amount of patient education, would more likely be empowered and therefore able to manage their condition, leading to a higher HRQoL, was investigated. There was no association between the level of empowering knowledge and the improvement in HRQoL, neither for the EQ-5D Index nor for the VAS. The countrywide comparison showed that higher levels of empowering knowledge had a significant positive influence on the VAS improvement only in Greece [42]. Torisho et al. (2019) [53] examined patient education before THR and found minor positive associations with an improvement in EQ-5D Index and VAS. Patient education was enabled by the Supported Osteoarthritis Self-Management Program, where participants were guided into groups, and therapy was adapted individually. Physiotherapy was a part of this program, in addition to patient education. A positive relationship between improvements in HRQoL and physiotherapy for the EQ-5D Index and VAS was revealed, but also with uncertain clinical relevance [53].

\section{Opioid usage}

Manalo et al. (2018) [43] evaluated the impact of preoperative opioid medication use on HRQoL changes after TKR. There was a significant HRQoL improvement for non-opioid users and no significant HRQoL improvement for opioid users on the EQ-5D Index and VAS. Even though the first finding indicated that non-opioid users benefit more from the surgery, no significant difference was found in the EQ-5D Index and VAS improvements between the opioid and non-opioid group [43]. Additional file 3 in the supplementary material provides detailed information about all alterable predictors.

\section{Non-Alterable Predictors Socioeconomic and demographic variables}

Age and gender The influence of age and gender on the EQ-5D Index and VAS in TKR and THR was evaluated by Jenkins et al. (2013) [40] with conflicting results. Although male gender was significantly associated with an increased VAS improvement, there was no impact on the EQ-5D Index change, whereas age had no significant impact on the VAS change, or on the EQ-5D Index. Generally, THR showed greater improvements than TKR [40]. THR was investigated by Peters et al. (2020) [47], and age and gender were regarded as being associated with an 


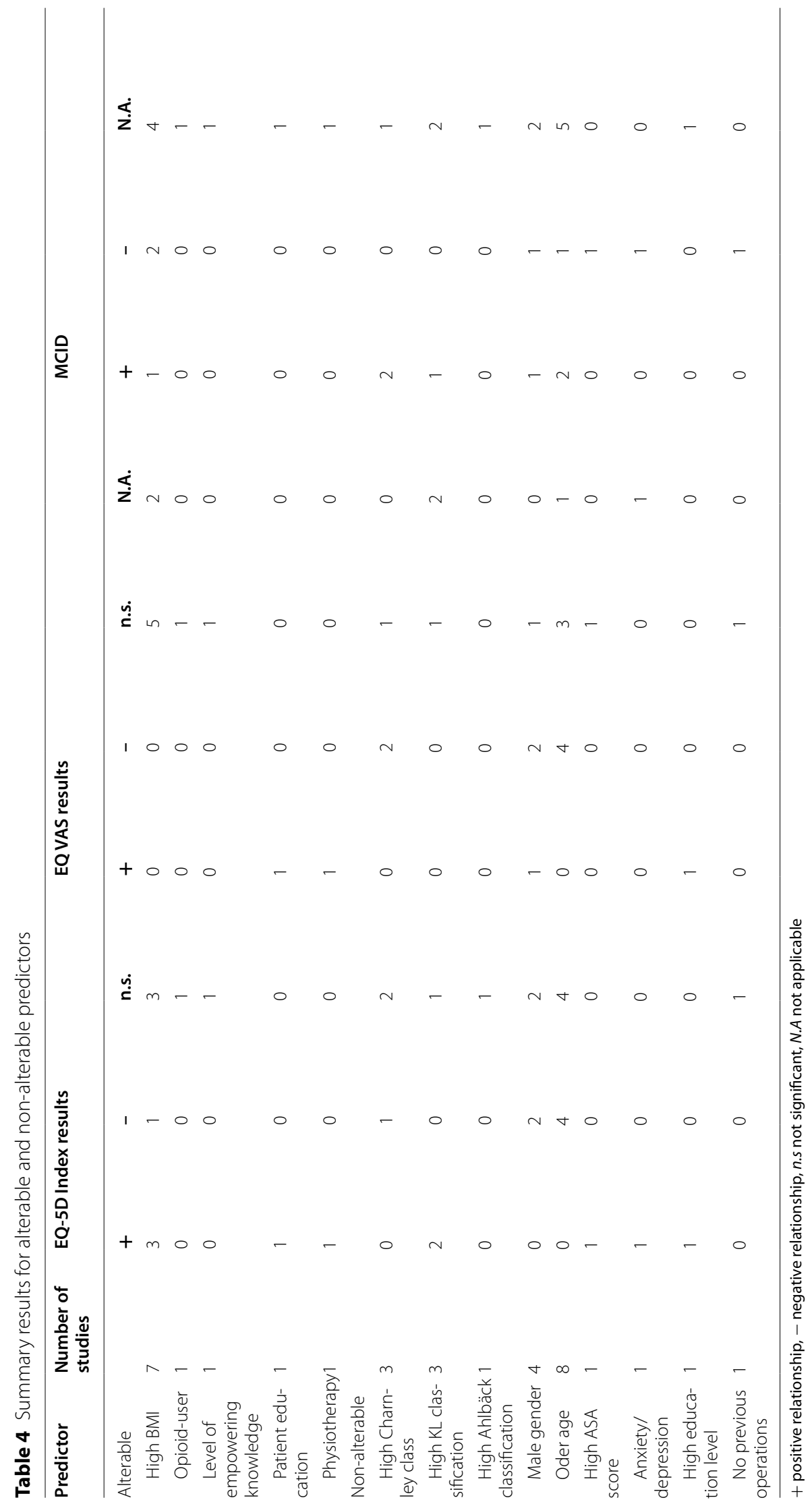


improvement in VAS and the EQ-5D Index. Women and patients $<60$ years benefited more from THR than men and older patients [47]. These findings were in line with the study from Rolfson et al. (2011) [49] who reported lower improvements for both, male gender and older age (>60 years) for VAS and EQ-5D Index, equally for THR. Conversely, Foster et al. (2015) [35] found no significant effects for either gender or age ( $<65$ years).

Age Gordon et al. (2014) [38] investigated the influence of age on HRQoL in THR. Age was divided into 6 age groups $(\leq 50,51-60,61-70,71-80,81-85$ and $>85$ years). Even though, improvements were found in VAS and the EQ-5D Index across all age groups, 20\% of patients older than 80 years were not able to improve their VAS score and $13 \%$ of patients older than 80 years did not improve their EQ-5D Index. Therefore, a nonlinear significant negative impact of age on VAS and EQ-5D Index improvements was revealed, starting in the late sixties. Additionally, low preoperative HRQoL had a significant effect on the EQ-5D improvements, with lower preoperative values resulting in larger gains [38]. Equally for THR, but for young patients ( $<30$ years) with OA or inflammatory joint disease, Mohaddes et al. (2019) [45] found significant VAS improvements compared to patients older than 30 years, whereas no significant impact was reported on the EQ-5D Index [45].

For TKR and unicompartmental knee replacements Williams et al. (2013) [54] indicated equally unbalanced results for the impact of age on HRQoL improvements. Patients were grouped into 5 age groups $(<55,55-64$, 54-74, 75-84 and $\geq 85$ years) and a significant linear impact was investigated for the EQ-5D Index with higher age resulting in lower EQ-5D Index changes. For the VAS, no significant influence of age was reported [54]. Joly et al. (2020) [41] indicated lower improvements for EQ-5D scores in younger patients $(<55$ years $)$ at 3 months postoperatively for TKR compared to patients aged $>70$ years. There was no significant difference at 1 year postoperatively. In contrast, for THR, the EQ-5D scores improved in younger patients ( $<55$ years) after 1 year, and the improvements were fewer after 3 months [41].

Level of education The educational level was examined by Greene et al. (2014) [39] as a predictor of HRQoL for THR. Patients with no education beyond primary school were assigned to the low education level, patients with no education beyond secondary school to the medium education level and patients with any postsecondary education to the high education level. The results indicated that patients with higher education attainment levels had significantly greater EQ-5D Index and VAS improvements in comparison to patients with lower or medium education attainment [39].

\section{Severity}

Charnley class Rolfson et al. (2011) [49], analyzed the influence of gender, age, and Charnley class on HRQoL changes for THR. Charnley class was revealed as a strong predictor for HRQoL measured with the VAS and the EQ-5D Index. Less improvement was reported, compared with a reference population, especially for class $\mathrm{C}$ [49]. In a similar way, Ostendorf et al. (2004) [46] evaluated the impact of Charnley classes on HRQoL changes for THR. The effect size was calculated by dividing the difference in pre- and postoperative EQ-5D scores by the preoperative score standard deviation. Medium effect sizes were found for the change in VAS for patients in class A and small effect sizes for patients in classes B and $C$. For the EQ-5D Index, a large degree of change was reported for patients in all classes. Patients in class A improved significantly more than patients in classes B and $C$, measured with the VAS. There were no significant differences between pre- and postoperative EQ-5D scores for the different classes [46]. Conversely, Foster et al. (2015) [35] investigated the impact of Charnley classes on the EQ-5D Index and VAS and found no significant differences between pre- and postoperative scores.

Kellgren Lawrence classification (KL) The KL score is a classification system for OA. The influence of KL on HRQoL improvements by TKR and THR were examined by Tilbury et al. (2016) [52]. Differences in the HRQoL changes of patients with KL grades $0-2$ in comparison to patients with KL grades 3-4 were evaluated. THR patients with a KL grade 3-4 showed greater HRQoL improvement than patients with a KL grade of $0-2$, although this result was only significant for the EQ-5D Index and not for the VAS. Results for TKR patients were not significant. Adjusted for age, gender, and BMI, as well as Charnley class for the THR group, no significant effects of KL grade on HRQoL changes were investigated, for either TKR or THR was investigated [52]. Scott et al. (2021) [50] also found no significant effects of the KL grade on HRQoL changes after TKR. In contrast, a study by Rehman et al. (2020) [48] evaluated whether severe radiographic OA was related to improvements in HRQoL after TKR. The results indicated that patients with severe OA, especially KL grade 4 , had more clinically meaningful improvement in their EQ-5D Index than patients with less severe OA [48]. 
Ahlbäck classification As well as the KL classification Scott et al. (2021) [50] investigated the Ahlbäck classification. Similar to the KL classification, they found no significant effect of the Ahlbäck classification on the improvement in the EQ-5D Index after TKR.

ASA score/no previous operations Peters et al. (2020) [47] examined the influence of the ASA score on the VAS and the EQ-5D Index for THA. The results showed diverging effects, with an improvement for patients with a high ASA score (III-IV) for the EQ-5D Index, but a non-significant result for the VAS. The clinical relevance was regarded to be very small. No influence of a previous operation was found, for either the EQ-5D Index, or the VAS [47].

Anxiety/depression Anxiety/depression as one item in the EQ-5D-3L was evaluated as a predictor for the EQ-5D Index by Galea et al. (2019) [36] following THR. One year postoperatively, smaller improvements were found in comparison to the rest of the cohort [36].

Detailed information about non-alterable predictors was given in the supplementary material, Additional file 4. The following table summarized the analyzed predictors for alterable and non-alterable predictors (Table 3).

\section{Discussion}

The evidence for preoperative predictors for changes in the EQ-5D Index or VAS was unclear. The most important main finding of this review was the effect that patients with higher BMI appeared to have increased improvements in their EQ-5D Index, preoperatively to postoperatively, especially for patients with a BMI $>40$. This finding should be weighed against the higher general- and specific risks of joint replacement surgeries for obese patients [56]. One study found that the delivery of patient education and physiotherapy was associated with better EQ-5D scores [53]. Significant results for non-alterable factors showed a tendency towards declining improvements for male gender (2 studies) [ 47 , 49], older patients ( 5 studies) [38, 47, 49, 54], conflicting results for severity (4 studies) $[47-49,52]$ and benefits for higher education (1 study) [39]. The effects of preoperative predictors seemed not to be understood. Although, as mentioned by Rolfson et al. (2011) [49], differences between pre- and postoperative EQ-5D distributions might prevent significant effects. In particular, comparing preoperative heterogeneous patient groups with postoperative homogeneous patient groups could prevent the identification of significant preoperative predictors. Furthermore, patients might be selected by hospitals and physicians, balancing high-risk patients with low-risk patients. This might have influenced regression results toward non-significant outcomes.

Considering comparison with MCIDs, only one study indicates clinical relevance, reporting the reverse effect for a higher BMI [36]. A limitation given different concepts of the MCID, and a range of values found, the MCID used was mostly not reported, but there were studies showing clinically relevant results regarding male gender, older age and severity. These findings were partly in line with previous reviews on predictors influencing postoperative HRQoL. For THR, determining preoperative factors that influence postoperative outcomes seemed to be very difficult, with vague results indicating that improvements were higher for worse preoperative function and more severe radiological OA [16]. Predictors for TKR, measured with the WOMAC, indicated ambiguous results, too. Older patients might benefit more from TKR than younger patients and female gender seemed to be advantageous, but there might also be no difference. The socioeconomic status had been reported to be beneficial [12], which was in accordance with this review. Very weak and no clear association for a variety of preoperative factors, like BMI, gender, comorbidities and preoperative function were found for TKR, measured with disease-specific HRQoL tools [13]. Predictors for functional outcomes were investigated by Buirs et al. (2016) [57] with diverse HRQoL instruments. Negative associations with high BMI and higher age were reported, whereas the association with good mental health seemed to be positive, and the impact on gender ambiguous. Chesham et al. (2017) [58] investigated whether preoperative physiotherapy improved the outcome of TKR. They found that more, high-quality, research was needed to draw a succinct conclusion. Thus, these mainly disease-specific literature reviews indicated a controversial discussion about predictors of HRQoL for THR and TKR. With the investigation of the generic instrument of the EQ-5D in this review, the controversies remain. The alterable predictors may be used by clinicians to improve the postoperative outcome of patients by taking preoperative measures.

\section{Limitations}

All studies were observational, in part lacking confounders, and mainly derived from routine data. The bias across studies might be strong, because the comparisons were made upon some simplifications. This review made no exclusion for the follow-up time after surgery. Hence, it would be possible that significant results differ for a follow-up time of 3 months compared with several years. Additionally, 12 studies applied the EQ-5D-3L, whereas others used the EQ-5D-5L or gave no information 
about the level. Although psychometric studies showed improvements in HRQoL measurement of the $5 \mathrm{~L}$-version over the $3 \mathrm{~L}$-version of the EQ-5D, this still cannot fully explain the opposite effects on HRQoL changes found for some of the predictors, for example the BMI [36].

Regarding the study design, the main database was the MEDLINE, there may be articles in additional databases that were not considered in this review. All articles were equally weighted. Some authors contributed to several articles with similar data and might not contradict themselves. Registry data were also applied by the same author group (e.g., Swedish registry data), which might cause bias towards these results.

Moreover, the MCID was reported in only 8 studies, with a calculation of the clinical relevance in several ways. The statistical effect size of Cohen's d [26] (0.2) and the anchor-based threshold of Walters et al. (2005) [23] (0.074) were mostly applied in slightly different versions and combinations. Owing to the heterogeneous thresholds, it remained unclear whether the changes in HRQoL were relevant. In future work, validation of the MCIDs used is thus highly important, with the respective strategies recently developed [59]. Furthermore, the response rates and the number of participants varied widely. The comparison was additionally impaired, because several statistical methods were applied.

\section{Conclusion}

There was limited evidence for definitive, preoperative predictors of HRQoL for TKR and THR. Alterable factors were mainly not significant, measured with the VAS. Higher BMI was associated with greater improvements in the EQ-5D Index. This was contradictory to the higher general- and specific risk of a joint surgery for obese patients, as reported by Kerkhoffs et al. (2012) [56] for infections and revisions in TKR. For non-alterable factors, male gender, older age and high Charnley class seemed to be negatively associated with HRQoL gains and thus pointed to additional potential risks, whereas $\mathrm{KL}$ and higher education appeared to be advantageous. The MCID was regarded to be uncertain. All the studies were observational and $42 \%$ of them were of very low quality. Higher quality studies are needed to identify predictors of change in EQ-5D Index and VAS following TKR and THR. This knowledge would support the optimal preoperative preparation of patients and assist with shared decision-making for arthroplasty. Further research is needed to support optimal preoperative preparation of patients as well as to provide better information for shared decision-making on arthroplasty.
Abbreviations

ASA: American Society of Anesthesiologists; BMI: Body Mass Index; VAS: EuroQoL visual analog scale; HRQoL: Health-Related Quality of life; KL: Kellgren Lawrence classification; MCID: Minimum Clinical Important Difference; OA: Osteoarthritis; THR: Total Hip Replacement; TKR: Total Knee Replacement; WOMAC: Western Ontario and McMaster Universities Osteoarthritis Index.

\section{Supplementary Information}

The online version contains supplementary material available at https://doi. org/10.1186/s12891-021-04981-4.

Additional file 1.

Additional file 2.

Additional file 3.

Additional file 4.

Acknowledgements

The authors would like to thank Prof. Dr. Reiner Leidl, Katharina Bredow and Ardit Gashi for feedback on an earlier draft of this article.

\section{Authors' contributions}

NK: Conceptualization, Formal analysis, Methodology, Writing - original draft. AM: Validation, Writing - original draft. PB: Supervision, Writing - review \& editing. CS: Formal analysis, Methodology, Project administration, Validation, Writing - original draft. The author(s) read and approved the final manuscript.

\section{Funding}

Open Access funding enabled and organized by Projekt DEAL. This work is part of the project "Munich Network Health Care Research - MobilE-Net" and was supported by the German Federal Ministry of Education and Research grant number 01GY1603A

Availability of data and materials

Not applicable.

\section{Declarations}

Ethics approval and consent to participate

Not applicable.

\section{Consent for publication}

Not applicable.

\section{Competing interests}

The authors declare that they have no competing interests.

\section{Author details}

${ }^{1}$ Ludwig-Maximilians-Universität München, LMU Munich School of Management, Institute of Health Economics and Health Care Management, Munich, Germany. ${ }^{2}$ Helmholtz Zentrum München, Institute of Health Economics and Health Care Management, Munich, Germany. ${ }^{3}$ Krankenhaus Barmherzige Brüder München, Akademisches Lehrkrankenhaus der Technischen Universität München, Munich, Germany.

Received: 20 August 2021 Accepted: 20 December 2021

Published online: 17 January 2022

\section{References}

1. Losina E, Walensky RP, Kessler CL, Emrani PS, Reichmann WM, Wright EA et al. Cost-effectiveness of total knee arthroplasty in the United States: patient risk and hospital volume. Arch Intern Med. 2009;169(12):1113-22.

2. Felix J, Becker C, Vogl M, Buschner P, Plötz W, Leidl R. Patient characteristics and valuation changes impact quality of life and satisfaction in total 
knee arthroplasty - results from a German prospective cohort study Health Qual Life Outcomes. 2019;17(1):180.

3. Verhaar J. Patient satisfaction after total knee replacement-still a challenge. Acta Orthop. 2020;91(3):241-2.

4. Brooks R. EuroQol: the current state of play. Health Policy. 1996;37(1):53-72.

5. Herdman M, Gudex C, Lloyd A, Janssen M, Kind P, Parkin D, et al. Development and preliminary testing of the new five-level version of EQ-5D (EQ-5D-5L). Qual Life Res. 2011:20(10):1727-36.

6. Janssen MF, Pickard AS, Golicki D, Gudex C, Niewada M, Scalone L, et al. Measurement properties of the EQ-5D-5L compared to the EQ-5D-3L across eight patient groups: a multi-country study. Qual Life Res. 2013;22(7):1717-27.

7. Jin X, Al Sayah F, Ohinmaa A, Marshall DA, Smith C, Johnson JA. The EQ-5D-5L Is Superior to the -3L Version in Measuring Health-related Quality of Life in Patients Awaiting THA or TKA. Clin Orthop Relat Res. 2019;477(7):1632-44.

8. Conner-Spady BL, Marshall DA, Bohm E, Dunbar MJ, Noseworthy TW. Comparing the validity and responsiveness of the EQ-5D-5L to the Oxford hip and knee scores and SF-12 in osteoarthritis patients 1 year following total joint replacement. Qual Life Res. 2018;27(5):1311-22.

9. Greene ME, Rader KA, Garellick G, Malchau H, Freiberg AA, Rolfson O. The EQ-5D-5L Improves on the EQ-5D-3L for Health-related Quality-of-life Assessment in Patients Undergoing Total Hip Arthroplasty. Clin Orthops Rel Res. 2015;473(11):3383-90.

10. Conner-Spady BL, Marshall DA, Bohm E, Dunbar MJ, Loucks L, Al Khudairy A, et al. Reliability and validity of the EQ-5D-5L compared to the EQ$5 \mathrm{D}-3 \mathrm{~L}$ in patients with osteoarthritis referred for hip and knee replacement. Qual Life Res. 2015;24(7):1775-84.

11. Alattas SA, Smith T, Bhatti M, Wilson-Nunn D, Donell S. Greater preoperative anxiety, pain and poorer function predict a worse outcome of a total knee arthroplasty. Knee Surg Sports Traumatol Arthrosc. 2017;25(11):3403-10.

12. Walker LC, Clement ND, Deehan DJ. Predicting the Outcome of Total Knee Arthroplasty Using the WOMAC Score: A Review of the Literature. J Knee Surg. 2019;32(8):736-41.

13. Harmelink KEM, Zeegers A, Hullegie W, Hoogeboom TJ, MWG N-VDS, Staal JB. Are There Prognostic Factors for One-Year Outcome After Total Knee Arthroplasty? A Systematic Review. J Arthroplast. 2017;32(12):38403853.e3841.

14. Karlson EW, Daltroy LH, Liang MH, Eaton HE, Katz JN. Gender differences in patient preferences may underlie differential utilization of elective surgery. Am J Med. 1997;102(6):524-30.

15. Pozzobon D, Ferreira PH, Blyth FM, Machado GC, Ferreira ML. Can obesity and physical activity predict outcomes of elective knee or hip surgery due to osteoarthritis? A meta-analysis of cohort studies. BMJ Open. 2018:8(2):e017689.

16. Hofstede SN, Gademan MG, Vliet Vlieland TP, Nelissen RG. Marang-van de Mheen PJ: Preoperative predictors for outcomes after total hip replacement in patients with osteoarthritis: a systematic review. BMC Musculoskelet Disord. 2016;17:212

17. Huber M, Kurz C, Leidl R. Predicting patient-reported outcomes following hip and knee replacement surgery using supervised machine learning. BMC Med Inform Decis Mak. 2019;19(1):3.

18. Teni FS, Burström K, Berg J, Leidl R, Rolfson O. Predictive ability of the American Society of Anaesthesiologists physical status classification system on health-related quality of life of patients after total hip replacement: comparisons across eight EQ-5D-3L value sets. BMC Musculoskelet Disord. 2020;21(1):441

19. Moher D, Liberati A, Tetzlaff J, Altman DG. Preferred reporting items for systematic reviews and meta-analyses: the PRISMA statement. PLoS Med. 2009;6(7):e1000097

20. Page P. Beyond statistical significance: clinical interpretation of rehabilitation research literature. Int J Sports Phys Ther. 2014:9(5):726-36.

21. King MT. A point of minimal important difference (MID): a critique of terminology and methods. Expert Rev Pharmacoecon Outcomes Res. 2011;11(2):171-84.

22. Copay AG, Eyberg B, Chung AS, Zurcher KS, Chutkan N, Spangehl MJ. Minimum Clinically Important Difference: Current Trends in the Orthopaedic Literature, Part II: Lower Extremity: A Systematic Review. JBJS Rev. 2018:6(9):e2.
23. Walters SJ, Brazier JE. Comparison of the minimally important difference for two health state utility measures: EQ-5D and SF-6D. Qual Life Res. 2005;14(6):1523-32.

24. Impellizzeri FM, Mannion AF, Naal FD, Hersche O, Leunig M. The early outcome of surgical treatment for femoroacetabular impingement: success depends on how you measure it. Osteoarthr Cartil. 2012;20(7):638-45.

25. Norman GR, Sloan JA, Wyrwich KW. Interpretation of changes in healthrelated quality of life: the remarkable universality of half a standard deviation. Med Care. 2003:41(5):582-92.

26. Cohen J. Statistical power analysis for the behavioral sciences. Hillsdale: Lawrence Erlbaum Associates; 1988

27. Guyatt G, Oxman AD, Akl EA, Kunz R, Vist G, Brozek J, et al. GRADE guidelines: 1. Introduction-GRADE evidence profiles and summary of findings tables. J Clin Epidemiol. 2011;64(4):383-94.

28. Guyatt GH, Oxman AD, Vist G, Kunz R, Brozek J, Alonso-Coello P, et al. GRADE guidelines: 4. Rating the quality of evidence--study limitations (risk of bias). J Clin Epidemiol. 2011;64(4):407-15.

29. Guyatt GH, Oxman AD, Kunz R, Brozek J, Alonso-Coello P, Rind D, et al. GRADE guidelines 6 . Rating the quality of evidence-imprecision. J Clin Epidemiol. 2011;64(12):1283-93.

30. Guyatt GH, Oxman AD, Montori V, Vist G, Kunz R, Brozek J, et al. GRADE guidelines: 5 . Rating the quality of evidence--publication bias. J Clin Epidemiol. 2011;64(12):1277-82.

31. Guyatt GH, Oxman AD, Kunz R, Woodcock J, Brozek J, Helfand M, et al. GRADE guidelines: 7. Rating the quality of evidence--inconsistency. J Clin Epidemiol. 2011;64(12):1294-302.

32. Guyatt GH, Oxman AD, Kunz R, Woodcock J, Brozek J, Helfand M, et al. GRADE guidelines: 8. Rating the quality of evidence--indirectness. J Clin Epidemiol. 2011:64(12):1303-10.

33. O'Connor D, Green S, Higgins JPT. Chapter 5: Defining the review question and developing criteria for including studies. In: GS HJPT, editor. The Cochrane Collaboration Cochrane Handbook of Systematic Reviews of Intervention. Volume 5.1.0; 2011

34. Baker P, Petheram T, Jameson S, Reed M, Gregg P, Deehan D. The association between body mass index and the outcomes of total knee arthroplasty. J Bone Joint Surg Am. 2012;94(16):1501-8.

35. Foster SA, Hambright DS, Antoci V, Greene ME, Malchau H, Kwon YM. Effects of Obesity on Health Related Quality of Life Following Total Hip Arthroplasty. J Arthroplast. 2015;30(9):1551-4.

36. Galea VP, Rojanasopondist P, Ingelsrud LH, Rubash HE, Bragdon C, Huddleston lii Jl, et al. Longitudinal changes in patient-reported outcome measures following total hip arthroplasty and predictors of deterioration during follow-up: a seven-year prospective international multicentre study. Bone Joint J. 2019;101-b(7):768-78.

37. Giesinger K, Giesinger JM, Hamilton DF, Rechsteiner J, Ladurner A. Higher body mass index is associated with larger postoperative improvement in patient-reported outcomes following total knee arthroplasty. BMC Musculoskelet Disord. 2021;22(1):635.

38. Gordon M, Greene M, Frumento P, Rolfson O, Garellick G, Stark A. Ageand health-related quality of life after total hip replacement: decreasing gains in patients above 70 years of age. Acta Orthop. 2014;85(3):244-9.

39. Greene ME, Rolfson O, Nemes S, Gordon M, Malchau H, Garellick G. Education attainment is associated with patient-reported outcomes: findings from the Swedish Hip Arthroplasty Register. Clin Orthop Relat Res. 2014;472(6):1868-76.

40. Jenkins PJ, Clement ND, Hamilton DF, Gaston P, Patton JT, Howie CR. Predicting the cost-effectiveness of total hip and knee replacement: a health economic analysis. Bone Joint J. 2013;95-b(1):115-21.

41. Joly DA, Ludwig T, Mahdavi S, Khong H, Piroozfar SG, Sharma R. Does Age Influence Patient-Reported Outcomes in Unilateral Primary Total Hip and Knee Arthroplasty? J Arthroplast. 2020;35(7):1800-5.

42. Koekenbier K, Leino-Kilpi H, Cabrera E, Istomina N, Johansson Stark A, Katajisto J, et al. Empowering knowledge and its connection to healthrelated quality of life: A cross-cultural study. Appl Nurs Res. 2016;29:211-6.

43. Manalo JPM, Castillo T, Hennessy D, Peng Y, Schurko B, Kwon YM. Preoperative opioid medication use negatively affect health related quality of life after total knee arthroplasty. Knee. 2018;25(5):946-51.

44. McLawhorn AS, Steinhaus ME, Southren DL, Lee YY, Dodwell ER, Figgie MP. Body Mass Index Class Is Independently Associated With HealthRelated Quality of Life After Primary Total Hip Arthroplasty: An Institutional Registry-Based Study. J Arthroplast. 2017;32(1):143-9. 
45. Mohaddes M, Nauclé RE, Kärrholm J, Malchau H, Odin D, Rolfson O. Implant survival and patient-reported outcome following total hip arthroplasty in patients 30 years or younger: a matched cohort study of 1,008 patients in the Swedish Hip Arthroplasty Register. Acta Orthop. 2019;90(3):249-52.

46. Ostendorf M, van Stel HF, Buskens E, Schrijvers AJ, Marting LN, Verbout AJ, et al. Patient-reported outcome in total hip replacement. A comparison of five instruments of health status. J Bone Joint Surg (Br). 2004;86(6):801-8.

47. Peters RM, van Steenbergen LN, Stewart RE, Stevens M, Rijk PC, Bulstra SK, et al. Which patients improve most after total hip arthroplasty? Influence of patient characteristics on patient-reported outcome measures of 22,357 total hip arthroplasties in the Dutch Arthroplasty Register. Hip Int. 2020;1120700020913208.

48. Rehman Y, Lindberg MF, Arnljot K, Gay CL, Lerdal A, Aamodt A. More Severe Radiographic Osteoarthritis Is Associated With Increased Improvement in Patients' Health State Following a Total Knee Arthroplasty. J Arthroplast. 2020;35(11):3131-7.

49. Rolfson O, Kärrholm J, Dahlberg LE, Garellick G. Patient-reported outcomes in the Swedish Hip Arthroplasty Register: results of a nationwide prospective observational study. J Bone Joint Surg (Br). 2011;93(7):867-75.

50. Scott CEH, Holland G, Keenan OJF, Ross LA, MacDonald DJ, Lawson GM, et al. Radiographic severity, extent and pattern of cartilage loss are not associated with patient reported outcomes before or after total knee arthroplasty in end-stage knee osteoarthritis. Knee. 2021;31:54-63.

51. Steinhaus ME, Buller LT, Romero JA, Lee YY, Figgie MP, McLawhorn AS. Body Mass Index Classification Is Independently Associated with Health-Related Quality of Life after Primary Total Knee Arthroplasty: An Institutional Registry-Based Study. J Knee Surg. 2020;33(4):399-409.

52. Tilbury C, Holtslag MJ, Tordoir RL, Leichtenberg CS, Verdegaal SHM, Kroon HM, et al. Outcome of total hip arthroplasty, but not of total knee arthroplasty, is related to the preoperative radiographic severity of osteoarthritis. Acta Orthop. 2016;87(1):67-71.

53. Torisho C, Mohaddes M, Gustafsson K, Rolfson O. Minor influence of patient education and physiotherapy interventions before total hip replacement on patient-reported outcomes: an observational study of 30,756 patients in the Swedish Hip Arthroplasty Register. Acta Orthop. 2019;90(4):306-11.

54. Williams DP, Price AJ, Beard DJ, Hadfield SG, Arden NK, Murray DW, et al The effects of age on patient-reported outcome measures in total knee replacements. Bone Joint J. 2013;95-b(1):38-44.

55. WHO, World Health Organization, Body mass index - BMI [http://www. euro.who.int/en/health-topics/disease-prevention/nutrition/a-healthylifestyle/body-mass-index-bmi].

56. Kerkhoffs GMMJ, Servien E, Dunn W, Dahm D, Bramer JAM, Haverkamp D. The Influence of Obesity on the Complication Rate and Outcome of Total Knee Arthroplasty: A Meta-Analysis and Systematic Literature Review. JBJS. 2012;94(20):1839-44

57. Buirs LD, Van Beers LW, Scholtes VA, Pastoors T, Sprague S, Poolman RW. Predictors of physical functioning after total hip arthroplasty: a systematic review. BMJ Open. 2016;6(9):e010725.

58. Chesham RA, Shanmugam S. Does preoperative physiotherapy improve postoperative, patient-based outcomes in older adults who have undergone total knee arthroplasty? A systematic review. Physiother Theory Pract. 2017;33(1):9-30

59. Devji T, Carrasco-Labra A, Qasim A, Phillips M, Johnston BC, Devasenapathy $\mathrm{N}$, et al. Evaluating the credibility of anchor based estimates of minimal important differences for patient reported outcomes: instrument development and reliability study. BMJ. 2020;369:m1714.

\section{Publisher's Note}

Springer Nature remains neutral with regard to jurisdictional claims in published maps and institutional affiliations.

Ready to submit your research? Choose BMC and benefit from:

- fast, convenient online submission

- thorough peer review by experienced researchers in your field

- rapid publication on acceptance

- support for research data, including large and complex data types

- gold Open Access which fosters wider collaboration and increased citations

- maximum visibility for your research: over $100 \mathrm{M}$ website views per year

At BMC, research is always in progress.

Learn more biomedcentral.com/submissions 